\title{
PRIMEIRA INFÂNCIA: A VISÃO DO BANCO MUNDIAL
}

\author{
HELEN PENN \\ School of Education and Community Studies, University of East London \\ Social Science Research Unit, Institute of Education, London University \\ h.penn@uel.ac.uk
}

Tradução: Fúlvia Rosemberg

\begin{abstract}
RESUMO
Este artigo examina a visão do Banco Mundial sobre a primeira infância como exemplo da globalização da infância. Argumenta que a globalização é caracterizada por um ponto de vista econômico neoliberal que exacerba a desigualdade entre nações ricas e pobres e entre ricos e pobres, dentro de cada país, bem como por um otimismo tecnológico-científico que enfatiza os benefícios das intervenções tecnológicas. O artigo mostra como esses dois aspectos da globalização influenciaram as políticas para crianças pequenas que o Banco Mundial vem promovendo ativamente. Recorre aos indícios apresentados pelo Banco Mundial para exemplificar as contradições inerentes a essa abordagem.

BANCO MUNDIAL - GLOBALIZAÇÃO - INFÂNCIA - CLASSE SOCIAL
\end{abstract}

\begin{abstract}
THE WORLD BANK'S VIEW OF EARLY CHILDHOOD. This paper explores the World Bank's view of early childhood as an example of the globalization of childhood. It argues that globalization is characterized by a particular neo-liberal economic approach which exacerbates the gap between rich and poor nations and between the rich and poor within countries; and by a technological/scientific optimism which stresses the benefits of technological interventions. It traces how these two aspects of globalization have influenced the policies towards young children that the World Bank is now actively promoting. It will draw on evidence presented by the World Bank to illustrate the contradictions inherent in such an approach.
\end{abstract}




\section{A INFLUÊNCIA DE SHARON STEPHENS}

Em Children and Politics of Culture, Sharon Stephens (1955) chama atenção para dois aspectos da vida das crianças. Em primeiro lugar, discute os impactos, nas crianças, de ações políticas e macroeconômicas. Nesse contexto, sua preocupação fundamental refere-se aos impactos da globalização no mundo minoritário (países de primeiro mundo, desenvolvidos e situados no hemisfério norte), cuja infância se tornou altamente individualizada, estratificada e consumista (Unicef, 2000). Mostra, também, que é no mundo majoritário* (países do terceiro mundo, em desenvolvimento, situados no hemisfério sul) que as crianças se tornaram as vítimas mais vulneráveis das políticas econômicas globalizantes. As estatísticas globais sobre crianças são realmente consternadoras. Um número inaceitável morre ao nascer ou logo depois'. Muitas das que sobrevivem têm acesso limitado a atendimento em educação e saúde, especialmente meninas dos países asiáticos pobres. Muitos dos bens consumidos diariamente no mundo minoritário, como alimentos, flores e roupas, dependem, para a sua produção, do trabalho infantil barato dos países pobres. Quase todas as cidades têm populações crescentes de crianças de rua. Observa-se um recrudescimento de doenças endêmicas outrora sob controle, como a tuberculose, além da incapacidade de se lidar com doenças novas como a Aids. Estima-se que uma em cada quatro crianças na África sub-saariana sofre de Aids, uma proporção realmente chocante. Além disso, milhões de crianças vivem na condição de refugiadas devido a guerras e desastres naturais (UNDP, 1999).

Segundo a autora, uma das maneiras pelas quais as políticas macroeconômicas se legitimaram foi invocando noções simplificadas e idealizadas de infância, família e comunidade, com o intuito de justificar ações que, na verdade, podem prejudicar a vida das crianças reais (Stephens, 1997). No seu entender, a cultura é simplesmente ignorada e as crianças, em toda parte, perseguem seus caminhos no terreno minado por definições conflitantes.

...que espécie de visões sociais e noções de cultura subjazem às afirmações presentes nos discursos sobre direito internacional de que cada criança tem direito a uma identidade cultural? Até que ponto essa identidade é concebida como singular e exclusiva, e que ordem de prioridades são reconhecidas nos casos em que várias

* As expressões "mundo minoritário" e "mundo majoritário", embora pouco utilizadas no Brasil com esta acepção, vêm sendo usadas na literatura internacional nos últimos anos (N. da E.).

I. Estimado em 7 milhões de crianças. 
formas de identidade cultural - regional, nacional, de minoria étnica ou indígena - se confrontam? (Stephens, 1995, p. 3)

Esses temas, os impactos de políticas macroeconômicas em crianças e o uso do conceito de "cultura" para explicar diferenças entre o mundo majoritário e o ocidental, instigaram a elaboração deste artigo. Eles são discutidos usando-se o exemplo das políticas do Banco Mundial destinadas à primeira infância.

O tema da primeira infância vem recebendo destaque crescente na agenda internacional. O recente Dakar framework for action, proposto no Fórum Mundial de Educação para Todos, adotou como primeira meta* "expandir e melhorar o cuidado e a educação da primeira infância, de modo integrado, especialmente para as crianças mais vulneráveis e desfavorecidas" (Unesco, 2000). A primeira infância é vista agora como momento privilegiado para intervenção, porque as crianças pequenas são consideradas maleáveis e suscetíveis à influência externa. $\bigcirc$ argumento de que o cérebro se desenvolve com mais intensidade nos primeiros anos de vida faz com que qualquer programa que vise ao desenvolvimento cerebral seja avaliado positivamente. Tais argumentos redencionistas são esmiuçados a seguir.

\section{BANCO MUNDIAL: UM PALADINO DA INFÂNCIA?}

O que é o Banco Mundial e por que deveria se interessar pelas crianças? $\bigcirc$ Banco é "propriedade de" I8I países-membros cujas perspectivas e interesses são representados por um conselho dirigente e um conselho diretor sediados em Washington. Banco Mundial é uma denominação genérica para numerosas instituições financeiras internacionais como o Banco de Pesquisa e Desenvolvimento (Bird), a Associação Internacional de Corporação Financeira e Desenvolvimento Internacional. Um país, para integrar o Bird, deve primeiramente associar-se ao Fundo Monetário Internacional (FMI). A intenção original, e louvável, do Banco Mundial e de seus antecessores e parceiros era a de promover um novo fluxo de desenvolvimento e a reconstrução das economias debilitadas pela Segunda Guerra Mundial. $\bigcirc$ Banco vem traduzindo essas intenções com liberalidade e, atualmente, tem interesses financeiros em quase todos os países "em desenvolvimento" ou em transição.

* A autora refere-se à primeira apenas no sentido ordinal e não como a mais importante das $\operatorname{metas}($ N. da E.). 
O seu maior acionista são os EUA, que detêm 16,49\% dos votos. Os Estados Unidos e outros quatro acionistas principais (França, Alemanha, Japão e Reino Unido que, juntos, detêm outros $16 \%$ dos votos) indicam, cada um, um diretor executivo. Os demais 19 diretores executivos são eleitos por um grupo de países, salvo o caso da China, da Federação Russa e da Arábia Saudita que também indicam um diretor.

Desafiado pelas críticas sobre o endividamento das nações pobres e a crescente desigualdade entre ricos e pobres, o Banco Mundial formula sua mais recente missão como "um cântico de idealismo": "Nosso sonho é um mundo livre da pobreza. Nossa missão é enfrentar a pobreza com paixão e profissionalismo com vistas a resultados duradouros."

E arrola como seus valores:

...honestidade, integridade e compromisso; trabalhar em equipe - com transparência e confiança; investir os outros de poder e respeitar as diferenças; assumir riscos e responsabilidades; ter prazer com o trabalho e a família.

Banco considera-se um agente intermediário entre as nações ricas do mundo minoritário e as nações pobres do mundo majoritário. Emprega alguns dos analistas mais conceituados em seus respectivos campos de atuação. $\mathrm{Na}$ área de educação e de desenvolvimento, por exemplo, recrutou pessoal respeitável de diversos países, fora dos Estados Unidos.

Apesar disso, há evidências de que não só tem sido malsucedido em seus esforços para diminuir a pobreza, como também de que pode estar contribuindo para torná-la mais aguda. Ainda que suas tentativas para medir a extensão da pobreza e, mais recentemente, de solicitar a visão dos pobres sobre sua experiência de viver a pobreza sejam, sem dúvida, procedimentos muito sofisticados, na raiz do problema encontra-se o próprio conceito de "desenvolvimento". O Banco Mundial reconhece, em seu relatório anual de 1999, que o sistema fiscal do mundo apresenta sérias deficiências, e que reformas institucionais e de governo (governance) são excessivamente lentas. Considera, entretanto, essas deficiências como falhas que podem ser sanadas, contanto que haja intervenção, ação orientada e especializada. Nesse sentido, alega que suas intervenções são efetivamente necessárias para alcançar estabilidade econômica e progresso, e que a ação de especialistas e técnicos pode resolver os problemas globais.

Seus críticos alegam, ao contrário, que os argumentos que consideram o desenvolvimento econômico e o progresso global como inexoráveis, neutros e universais (culture-free) são tão falhos que se tornam insustentáveis (Chossudovsky, 1997; 
Hancock, 1989; George, Sabelli, 1994; Sachs, 1999; Shiva, 2000; Sklair, 1994; Stirrat, 1999; Rahnema, 1997; Rist, 1997; Woordward, 1992). Em particular, alega-se que o endividamento e a renegociação de dívidas internacionais "violam os princípios mais importantes do império da lei" (Raffer, 1992)². O projeto de Bretton Woods, uma coalizão de organizações não governamentais que monitora os resultados do Banco Mundial e divulga um resumo bimensal de artigos sobre vários aspectos da sua política, é extremamente crítico (www.brettonwoods.org). Um grupo de autores aí citados chega a afirmar que

não se pode apontar região no mundo em que o Banco tenha sido bem-sucedido na implementação das políticas que promove [...] Há inúmeros exemplos em que tanto os pobres como os trabalhadores não conseguiram participar dos lucros do desenvolvimento econômico. (Weisbrot et al., 2000)

Eles sugerem que as evidências estatísticas usadas para sustentar ou apoiar a política do Banco Mundial estão comprovadamente erradas.

Será que as políticas econômicas preconizadas pelo Banco Mundial prejudicam as crianças? Há evidências irrefutáveis de que a desigualdade entre países ricos e pobres está aumentando e de que a população pobre do mundo está se tornando mais pobre (UNDP, 1999). As crianças são mais intensamente afetadas pela pobreza como também são particularmente susceptíveis a cortes nos serviços de infraestrutura, tais como os de saúde e educação. Scheper-Hughes (1993), por exemplo, alega que quando a Junta Militar tomou o poder no Brasil, instituindo um novo regime econômico, houve uma "limpeza" de crianças nas áreas mais pobres do nordeste do Brasil em que Scheper estivera trabalhando, evidenciada pelo aumento da mortalidade infantil. A transição para uma economia de mercado, em países comunistas, levou a uma queda no acesso à educação de modo geral e, em alguns casos, de maneira drástica (Unicef, 1999). Muitos outros autores associaram as políticas econômicas neoliberais (particularmente quando introduzidas abruptamente) ao crescimento da pobreza e ao sofrimento das crianças (De Vylder, 1992; Rampal, 1999; Woodward, 1992).

O Banco Mundial reconhece que a qualidade da educação está caindo e que a mortalidade infantil está aumentando no mundo mas, como foi apontado anterior-

2. O grupo de campanha Jubileu 2000 afirma que uma boa parte do endividamento advém de empréstimos a regimes corruptos e ditatoriais como os de Mobuto, Suharto, dos generais brasileiros e do apartheid da África do Sul. 
mente, considera que essa situação decorre muito mais de falhas no ajuste técnico de sua implantação do que, propriamente, de uma falha intrínseca à política econômica neoliberal. Por conseqüência, estão focalizando mais empréstimos em projetos educacionais e de desenvolvimento social. Um recente folheto promocional alega que "O Banco Mundial está plenamente comprometido em favorecer de modo dinâmico e abrangente a melhoria da qualidade de vida das crianças" (World Bank, 2000, p. I). Essa reorientação gradativa do foco de sua ação levou o Banco Mundial à adoção de programas para a primeira infância, o que passarei a discutir.

Banco Mundial até agora emprestou mais de um bilhão de dólares para apoiar uma série de programas de desenvolvimento e cuidado à primeira infância em todo o mundo, inclusive em países como Bolívia, Colômbia, Brasil, El Salvador, Índia, Indonésia, Nigéria, Uganda, Marrocos e Casaquistão. Além de manter um website em atividade com material sobre os primeiros anos da infância ${ }^{3}$, comissiona periódicos e promove o tema em publicações e conferências regionais e globais. $\bigcirc$ Banco Mundial considera-se importante promotor do debate sobre a primeira infância e, reciprocamente, é objeto de lobby de muitas organizações que o encaram como um protagonista central no campo. O próprio Banco afirma ser

...a maior fonte individualizada de fundos externos para a saúde e a educação em países em desenvolvimento. Cada vez mais, grande parte desse investimento tem sido direcionada para ajudar a primeira infância - o capital humano do futuro. (World Bank, 2000, p. I)

\section{O DESENVOLVIMENTO NORMAL DA PRIMEIRA INFÂNCIA}

Que conceito de primeira infância subsidia as políticas do Banco Mundial? $\bigcirc$ modelo de desenvolvimento humano utilizado para promover o ECD (Early Childhood Care and Development) - Desenvolvimento e Cuidado da Primeira Infância - reflete o modelo de desenvolvimento econômico. A teoria do capital social sustenta grande parte da atenção recente do Banco Mundial ao tema do bem-estar social: aumentar o capital social de uma pessoa, sua capacidade de vincular-se a redes sociais e compartilhar riscos levaria a maior competitividade e produtividade (IDS, 2000). As metáforas econômicas e tecnocráticas da teoria do capital social são usadas para explicar e justificar o interesse do Banco Mundial pelas

3. Para maiores informações, ver www.worldbank.org/children 
crianças e pela infância. Para o Banco, o objetivo da infância é tornar-se um adulto plenamente produtivo, o "capital humano" do futuro.

Mary Eming Young, especialista sênior em Saúde Pública do Banco Mundial e responsável por grande parte de suas publicações, justificando as políticas para a criança pequena, ao revisar as políticas de ECD "em todo o mundo", chegou à seguinte conclusão:

As evidências sugerem que os programas de ECD são eficazes quando enfrentam problemas vitais ao desenvolvimento do ser humano, tais como a desnutrição entre crianças com menos de cinco anos, o desenvolvimento cognitivo deficiente e o despreparo para a educação primária... intervenções em educação infantil podem aumentar a eficiência da educação primária e secundária, podem contribuir para maior produtividade e renda futuras, bem como reduzir o custo de serviços públicos e do atendimento à saúde. As deficiências causadas nos indivíduos pela desnutrição durante os primeiros anos de vida e por cuidados inadequados podem afetar a produtividade no trabalho e o desenvolvimento econômico em toda a sociedade. Intervenções planejadas e implementadas adequadamente para a criança pequena podem acarretar benefícios multidimensionais. (Young, 1998, p. 202-210)

Deixando de lado a questão da desnutrição ${ }^{4}$, o que seriam essas intervenções planejadas adequadamente? As conclusões de Young referem-se exclusivamente a programas norte-americanos. Não há uma única menção à experiência de outros países desenvolvidos, ainda que exista uma farta documentação, proveniente da Europa e de outras partes do mundo, sugerindo que as concepções de programas para a primeira infância podem ser muito diferentes das norte-americanas. $\mathrm{Na}$ verdade, os Estados Unidos podem ser considerados um péssimo exemplo para educação e cuidado infantil, tanto da perspectiva dos profissionais como da de seus usuários, inclusive das crianças (EU, 1998; OECD, 2000; Penn, 2000).

Mais recentemente, o World Bank Institute, extensão do Banco criada em 1955 para treinar funcionários graduados envolvidos com planejamento e desen-

4. Nesse tipo de análise, a desnutrição das crianças não está diretamente ligada à garantia de alimento nem ao empobrecimento. $\bigcirc$ "ambiente" é considerado em grande parte como dado. A proposta é que mães e outras pessoas que cuidam das crianças consigam atenuar as deficiências ambientais. Maud Pember Reeves (Virago, 1990) mostrou em sua análise sobre alimentação em famílias pobres de Lambeth, no começo do século passado, que mães pobres simplesmente não podiam alimentar seus filhos, mas foram tratadas pelos profissionais médicos como mães descuidadas e/ou sem instrução. Grande parte da literatura sobre desnutrição de crianças em países pobres endossa esse ponto de vista (ver, também, Wachs, McCabe, 1998). 
volvimento, execução de políticas, análise de investimento e implementação do projeto em países-membros em desenvolvimento (Evans, Myers, llfeld, 2000), publicou um manual "definitivo" para programas destinados à primeira infância. Esse guia também recebeu o imprimatur das doze principais agências financiadoras internacionais envolvidas com a primeira infância - incluindo Unesco, Unicef, Usaid, Associação Cristã de Moços, Plan International e o Banco Interamericano de Desenvolvimento - sendo divulgado por uma organização que recebe fundos múltiplos, o Consultative Group on Early Childhood Care and Development.

O manual levou vários anos para ser produzido e, no início, valeu-se de guias anteriores - elaborados pela Unicef e por outras agências. Contém algumas sugestões úteis e até um tanto radicais, já que foram incluídas novas informações e idéias. Embora mencione os direitos das crianças, retrocede ao propor definições de caráter geral quanto às necessidades infantis. Sua proposta mais destacada (e do CDRom que o acompanha) é a das denominadas "práticas apropriadas ao desenvolvimento" (Developmentally Appropriate Practice). Tais preceitos de interpretação e de práticas modelados para crianças nos Estados Unidos são vistos como perfeitamente legítimos para o mundo majoritário (subdesenvolvido, do Sul, do Terceiro Mundo). Na verdade, os autores alegam que a única evidência e experiência válida provém dos EUA, pois ninguém mais testou os pressupostos relativos à primeira infância com a mesma intensidade (não levando em conta que outros países desenvolvidos possam não considerar válido ou necessário tal procedimento para legitimar seus gastos com crianças pequenas).

Pedagogos norte-americanos de destaque têm afirmado que "as crianças, em muitos aspectos, são semelhantes em qualquer lugar, e quem as ensina tem muitos pontos de vista semelhantes" (Weikart, 1999; Katz, 1998). Foi a National Association for the Education of Young Children (Naeyc), principal porta-voz de profissionais de educação infantil nos Estados Unidos, quem cunhou a expressão "práticas apropriadas ao desenvolvimento"* (Bredekamp, 1987, 1998). O manual, produzido e atualizado pela Naeyc, arrola os estágios de desenvolvimento por que passam as crianças e os contextos familiares amplos em que a aprendizagem ocorre. Perpetua o estereótipo da experiência dividida em "fatias"5 ou aspectos: físico,

* Em inglês, Development Appropriate Practice - DAP. O conceito será referido várias vezes pela sigla no artigo (N. da E.).

5. No original, a metáfora usada foi pie (torta). A autora informa em nota que tal termo foi empregado por um grupo de educadores na Nova Zelândia para ironizar essa representação convencional da experiência das crianças (May apud Penn, 2000). 
intelectual, emocional e social. Enumera as práticas que os adultos devem adotar a fim de possibilitar às crianças vencerem os estágios de desenvolvimento com sucesso. Assume que esses estágios e as práticas associadas são semelhantes em toda parte. A "cultura" produziria apenas pequenas variações.

Resultados de pesquisas efetuadas no campo da Psicologia do Desenvolvimento são evocados para apoiar e justificar essa abordagem. Para justificar cada aspecto do comportamento e da prática recorre-se a "evidências científicas". Os resultados de estudos empíricos, por mais específicos que tenham sido, podem ser generalizados para construir a imagem do que sejam necessidades das crianças $^{6}$. Essa noção de "práticas apropriadas ao desenvolvimento" é recorrente em manuais e livros para profissionais da educação infantil em todo o mundo. $\bigcirc$ Banco Mundial, em seu próprio manual de programação e em outras publicações, confere-lhe a posição de referência-chave. $\bigcirc$ Banco Mundial e outras agências doadoras, supõem que as crianças pequenas passam pelos mesmos estágios de desenvolvimento nas mesmas idades, tanto em regiões remotas do $\mathrm{Nepal}^{7}$ como em Chicago. Para essa concepção, o que define a primeira infância é a capacidade cerebral. "Se o cérebro se desenvolve bem, o potencial de aprendizagem aumenta e as possibilidades de fracasso na escola ou em período posterior da vida diminuem." (Evans, Myers, Ilfeld, 2000, p. 7) Segundo o manual de programação, as necessidades "culturais" devem ser respeitadas, mas ao mesmo tempo "práticas adequadas ao desenvolvimento" devem ser propostas por programadores esclarecidos (idem, p. 3).

Uma leitura cuidadosa dos textos sobre "práticas adequadas ao desenvolvimento" e de documentos similares sugere que se apropriam da literatura de pesquisas - complexa, muito específica e, por vezes, contraditória com pouco cuida-

6. Por exemplo, experiências realizadas nos anos 50 sobre o córtex visual de gatinhos, que mostravam que vendar gatinhos recém-nascidos prejudicava irremediavelmente seu desenvolvimento visual, foram citadas como evidências relevantes em importante relatório canadense para defender programas de intervenção precoce em crianças com menos de três anos! (Mustard, McCain, 1999)

7. Um recente relatório sobre ECD em quatro aldeias remotas do Nepal, encomendado conjuntamente por um grupo internacional de agências de apoio, também cita uma série de estudos norte-mericanos e usa para programação as mesmas categorias relativas aos aspectos físicos, emocionais, intelectuais e sociais ("Childrearing, Child Rights and Early Childhood programming in Nepal: a Developing Approach to Working with Parents". Manuscrito inédito). 
do, "pinçando e misturando os ingredientes". De um modo ${ }^{8}$ mais crítico, e em nível de metanálise, tal concepção assenta-se em certos pressupostos de sociedade que incorporam o primado do individualismo e da individualidade, a existência de um lar nuclear estável, com uma pessoa cuidadora disponível e uma única criança dependente como foco da atenção do adulto; a necessidade de encorajar a escolha a partir de uma ampla gama de bens materiais, a separação entre mente e corpo e assim por diante (Penn, 1999). As práticas defendidas não foram criadas de modo científico ou neutro (mesmo que isso fosse possível), mas, ao contrário, foram alicerçadas em pressupostos específicos sobre a infância e a sociedade. As "práticas adequadas ao desenvolvimento" poderiam ser descritas mais precisamente como "de que modo entender e criar seu filho como um anglo-americano". A despeito de suas deficiências quanto à representatividade e ao tipo de pesquisa em que se baseiam, as "práticas adequadas ao desenvolvimento" têm sido amplamente utilizadas.

Sharon Stephens também tece comentários sobre o equívoco de se utilizar os Estados Unidos como modelo para educar as crianças. Trata-se de uma sociedade cujos valores podem ser considerados representativos de um neoliberalismo econômico extremo. É uma sociedade que adota uma economia política específica, baseada em pressupostos sobre o papel do indivíduo e do Estado e das relações entre ambos. Por exemplo, considera normais as disparidades intensas entre ricos e pobres e interpreta tais desigualdades como sendo decorrentes de conquistas ou fracassos pessoais. Dispõe de um dos mais desiguais e injustos sistemas de educação infantil (OECD, 2000), bem como do sistema de justiça mais punitivo - a mais alta porcentagem de pessoas presas e o maior número de execuções entre os países desenvolvidos. Os EUA recusaram-se a assinar a declaração da ONU sobre os direitos da criança (o único país no mundo, além da Somália, a assumir essa

8. Por exemplo, uma das descobertas citadas com maior freqüência é a de Chugani e seus colegas ( 1987 ) sobre o desenvolvimento cerebral. $\bigcirc$ estudo relata os resultados dos exames de PET sobre 29 crianças epiléticas, de idade entre 5 dias e 15 anos, muitas das quais medicadas desde a infância e outras apenas no dia em que passaram pelo exame. Seus resultados foram comparados com os de sete adultos normais de idade entre 19 e 30 anos. Apesar de basear-se em amostra muito limitada e atípica, como Bruer ( 1999) observa, o estudo é tido como exemplo paradigmático de como a neurociência provê "dados confiáveis" sobre os primeiros três anos de vida, segundo o estudo de 1987, de PET, por parte de Chugani, ...um dos mais superinterpretados trabalhos dos últimos 25 anos. É citado em "práticas adequadas ao desenvolvimento" e também por Evans, Myers e llfeld (2000) e Young ( 1998) como fonte primária de evidências sobre o funcionamento do cérebro. 
postura), bem como não aceitam a criação de um tribunal internacional de direitos humanos, apesar da considerável pressão internacional ${ }^{9}$. Os Estados Unidos também são o principal acionista do Banco Mundial, embora a influência de sua ideologia neoliberal e pró-corporativista se exerça para além da votação dos acionistas.

\section{PROMOVENDO INTERVENÇÕES PRECOCES}

Os consultores do Banco Mundial têm aceitado de maneira pouco crítica os pressupostos das "práticas adequadas ao desenvolvimento". Estas nos apresentam algo como "um núcleo de criança", encarnação de um cérebro, ainda muito centrado em si mesmo, sobre quem os adultos agem de modo benéfico ou não. Os adultos que educam as crianças pequenas, como pais, professores, são vistos como exercendo uma influência ímpar, profunda e formadora durante os primeiros anos de vida de uma criança. $O$ padrão e as etapas do desenvolvimento infantil parecem ser os mesmos em toda parte, mas consideram que podem ser acelerados por modos especiais de intervenções dos adultos, como aqueles previstos em programas educacionais para pais; ou, ao contrário, concebem que o desenvolvimento pode ser desacelerado e mesmo obstruído pela ausência dessas intervenções. Reciprocamente, "a paternidade deficiente", se não tratada, pode acarretar nas crianças, baixa auto-estima, falta de aspirações e comportamento anti-social. Os efeitos fisiológicos da desnutrição mesclam-se com os efeitos psicológicos de uma "paternidade frustrada", e a resposta para ambos é uma intervenção mais apurada e cuidadosamente ajustada. Consideram, ainda, que basta que os profissionais encontrem o programa certo para os pais e o tipo correto de intervenção a ser usado quando as crianças ainda são bem pequenas e maleáveis e seu cérebro ainda não está totalmente desenvolvido, para que muitos dos efeitos da pobreza sejam compensados. Esses programas de intervenção precoce, e os pressupostos sobre os quais repousam,

9. Presumivelmente, os Estados Unidos agem desse modo porque seus legisladores consideram as opiniões do resto do mundo inconseqüentes. O poder econômico e militar dos Estados Unidos é tal que está numa posição indevassável para impor sua própria posição ideológica. Um artigo recente no jornal Guardian recebeu respostas de norte-americanos a um artigo que levantava as mesmas questões sobre a sociedade norte-americana. Por exemplo: "Não ligo para países a não ser o meu. Os Estados Unidos usam mais recursos mundiais do que qualquer outro país - e daí nós estamos alimentando o mundo e nossa economia sustenta qualquer economia de araque do terceiro mundo. Não precisamos de vocês. Vocês precisam de nós. Está na hora de vocês lixo europeu nos respeitarem como merecemos" (OECD, 2000, p. 17). 
têm sido criticados severamente (Rich Harris, 1995; Bruer, 1999; Kagan, 1998), mas essas críticas constituem apenas um pequeno ataque ao discurso dominante.

Por exemplo, a estratégia do Banco Mundial para o desenvolvimento infantil (Early Child Development - ECD) na África, ao mesmo tempo que reconhece próforma a existência de problemas estruturais tais como dívida externa, guerra e Aids, conclui que a desnutrição infantil é "em grande parte devida às práticas impróprias de alimentação das crianças, à alta taxa de morbidade e às práticas insatisfatórias de cuidado para com elas" (World Bank, 1999).

Mesmo se aceitasse o argumento de que em última instância a pobreza não é estrutural, e de que o ECD é uma forma eficaz de intervenção para combater a pobreza, resta a questão relativa ao financiamento dos programas. Os Estados Unidos são considerados o modelo de uma economia muito bem-sucedida e competitiva, embora a média salarial não tenha aumentado em 27 anos (Stirrat, 1999; Weisbrot et al., 2000). Qualquer regulamentação é considerada, na maioria das vezes, uma interferência indevida. Essa visão do Estado como essencialmente incapaz ou, no mínimo, tendo que trabalhar em estreita parceria com a iniciativa privada estende-se à educação e ao ECD. Na Europa Ocidental e Oriental os programas de ECD estão bem consolidados como serviços financiados e regulamentados pelo Estado. Nos EUA, porém, quase não existem serviços públicos de ECD (OECD, 2000). Do mesmo modo que ocorre nos Estados Unidos, no contexto do Banco Mundial também há pouca aceitação da necessidade de atuação do Estado, exceto quando destinada a uma determinada minoria formada pelos mais pobres; e, mesmo nesse caso, a maioria das intervenções ocorre através de convênio com provedores diversos, quase sempre sem regulamentação.

O setor privado é, pois, incentivado pelo Banco Mundial a investir em programas de ECD. Um documento recente, encomendado pelo Banco, compila os argumentos a favor dos investimentos privados em ECD (Myers, 2000, p. 4). Myers lista seis argumentos que justificariam o apoio a programas de ECD: direitos humanos, valores morais e sociais, produtividade econômica, contenção de despesas, eficácia do programa e, finalmente, eqüidade social. $\bigcirc$ argumento relativo aos direitos humanos é considerado em grande parte incompatível com uma abordagem neoliberal corporativista. Em vez disso, Myers sugere um modelo mais "prático", em que diferentes instituições poderiam ser agrupadas, e conclui que há muitas oportunidades para a ação de caráter macro e microfilantrópico, no intuito de promover o ECD. 
Estudiosos brasileiros, tais como Rossetti-Ferreira (2000) e Rosemberg $(2000)^{10}$, ao pesquisarem os efeitos do investimento em programas de ECD no Brasil, argumentam de modo convincente que, apesar das reivindicações para que especialistas avaliem propostas de programas de ECD, os investimentos do Banco Mundial e das instituições parceiras, planejados para redimir a pobreza, promovem modelos de educação infantil muito inferiores aos aceitáveis para as pessoas mais prósperas. Pouco fazem para ajudar os pobres, especialmente na medida em que endossam a exploração de mulheres, profissionais da educação infantil, em serviços com baixa remuneração. Na realidade, os indícios sugerem que a promoção desses "programas a baixo custo" tem sido usada cinicamente para reduzir os investimentos em educação infantil. Um dos primeiros programas de ECD a "baixo custo", implantado em Medellin, Colômbia, sofreu um esvaziamento quando as mulheres contratadas como "mães crecheiras" (childminders) protestaram devido à falta de benefícios e segurança. A Colômbia está caindo numa anarquia que provavelmente não pode ser impedida pelos programas de ECD. No entanto, os programas desse país são considerados ainda como um tipo de intervenção bem-sucedida" ${ }^{\prime}$. Os modelos de investimento do Banco Mundial em ECD de fato serviram para reproduzir pressupostos norte-americanos sobre a aceitabilidade de imensas disparidades entre ricos e pobres ${ }^{12}$.

\section{CONCLUSÃO}

Não se deve exagerar. Relativamente poucas crianças do mundo terão uma experiência vagamente próxima à de um programa de ECD antes de começar a

10. A autora está se referindo a comunicações apresentadas por essas duas autoras no Congresso Internacional de Psicologia realizado na Suécia em agosto de 2000. Ambas as comunicações estão publicadas nesta edição, precisamente, nas páginas 25 e 65.

I I. Burke (2000) relata que a guerra na Colômbia desalojou milhares de crianças, inclusive em Medellin, onde foram lançados os programas de ECD. Os conceitos nos quais o programa se baseia são: I. o desenvolvimento saudável de crianças pequenas depende da qualidade do ambiente em que elas crescem, isto é, da família e da comunidade, especialmente nos primeiros anos de vida; 2 . para alcançar desenvolvimento social sustentável e integrado, cada indivíduo e a comunidade devem estar envolvidos na geração de seus próprios processos de desenvolvimento...; 3. as mudanças deveriam ser articuladas com e no entorno da família (Unesco, 1998, p. 67).

12. Apesar de seu PIB extremamente baixo, de longe os melhores indicadores nas áreas da educação e da saúde na América Latina vêm de Cuba, um fato pouco digerível em termos neoliberais. 
escola, se é que chegarão à escola. Não obstante, há um tipo de cartel de agências internacionais de doação, incluindo Unicef e Unesco, muito influenciadas pelo Banco Mundial, para o qual os programas integrados de intervenção precoce, que combinam a educação dos pais e a estimulação de crianças pequenas, com programas de saúde e desenvolvimento da comunidade, constituem um modo efetivo para combater a pobreza' ${ }^{13}$. Esses programas de ECD são vistos como preventivos. Eles produziriam, a longo prazo, adultos mais produtivos, acarretando, por sua vez, uma economia mais produtiva.

Poucos discordarão de que as crianças pequenas se beneficiam dos espaços protegidos em que possam se deslocar e brincar quando seu ambiente é perigoso. Também não discordarão de que o tipo de pobreza que afeta muitas crianças do mundo - e suas famílias - seja debilitante e prejudicial. Essas questões podem e devem ser abordadas em todos os níveis, quer no primeiro quer no terceiro mundo, sendo que as agências doadoras internacionais desempenham, de fato, um papel importante em sua abordagem. Mas a retórica sobre os programas para os primeiros anos de infância é enganadora. Ela é redencionista - o mundo é um lugar difícil de reformar, mas as crianças são inocentes e ainda não estão formadas; realmente podemos ser agentes transformadores se pudermos chegar a tempo e converter seus pais quanto à maneira melhor de educá-las. Além disso, é importante assinalar que essa retórica é diversionista. Como Kagan ressaltou em relação aos Estados Unidos, a retórica é um meio de negar uma verdade inaceitável.

...muitas pessoas acreditam no determinismo infantil (porque) ele ignora o poder do pertencimento à classe social. Embora a classe social de uma criança seja o melhor indicador da futura profissão, de realizações acadêmicas e saúde psíquica, os norteamericanos querem crer que sua sociedade é aberta, igualitária, sem fronteiras rígi-

13. Essa idéia de desenvolvimento também permite um fundamento lógico para programas de intervenção precoce nos Estados Unidos e no Reino Unido. Em vez de se concentrarem em problemas estruturais de pobreza e eqüidade, os governos enfatizam as noções de "exclusão social" e de "capital social". Essas abordagens destacam a necessidade de os próprios pobres agirem. Por exemplo, por meio da melhoria de seu programa Sure Start (Início Seguro), o Ministério da Fazenda britânico se impôs metas tais como melhorar o bem-estar social e emocional das crianças investindo nas habilidades dos pais; na saúde, especialmente os números de crianças de baixo peso ao nascer e uma diminuição da mortalidade infantil; alcançar 90\% de normalidade na linguagem e desenvolvimento; melhorar a disposição para o aprendizado, e fortalecer as famílias e comunidades "naturais". Isso deve ser realizado com intervenções precoces nas comunidades pobres, tais como visitas ao lar e educação dos pais e não por manutenção da renda familiar ou regeneração do emprego. 
das de classe. Reconhecer o poder da classe é questionar esse cânone ético. (Kagan, 1998, p. 147)

mesmo pode ser dito acerca da promoção de programas para a primeira infância por parte do Banco Mundial. A premissa de que uma dose de "práticas adequadas ao desenvolvimento" da criança em Uganda ou no Casaquistão pode tratar com eficiência a pobreza e a desigualdade naqueles países é ridícula. Stephens ( 1997 ) mostra como os Estados Unidos, no auge da Guerra Fria, usaram imagens de crianças brancas de classe média em campanhas publicitárias para legitimar uma política com armas e testes nucleares que prejudicaram diretamente muitas crianças pertencentes a comunidades marginalizadas. $\bigcirc$ Banco Mundial é, de modo semeIhante, capaz de usar a figura da criança inocente, cujo cérebro será alimentado, em termos de nutrição e cognição, por programas de ECD delineados nos Estados Unidos. Dessa forma, o Banco Mundial e suas agências doadoras evitam assumir o grande dano que as políticas neoliberais vêm impingindo às crianças pobres do mundo majoritário e seu fracasso no perdão da dívida externa.

\section{REFERÊNCIAS BIBLIOGRÁFICAS}

BREDEKAMP, S. (ed.). Developmentally appropriate practice in early childhood programmes serving children birth through age 8. Washington: National Association for the Education of Young Children, $1987 / 98$.

BRUER, J. The Myth of the first three years. a new understanding of early brain development and lifelong learning. New York: The Free Press, 1999.

BURKE, J. Broken victims of a Nasty little war seek refuge in the swollen slums. Observer Newspaper, 29.10.2000. p. 24.

CHUGANI, H. T.; PHELPS, M. E.; MAZZIOTA, J. C. Positron emission tomography study of human brain function development. Annals of Neurology, n. 22, p. 487-497, 1987.

CHOSSUDOVSKY, M. The Globalisation of poverty. impacts of IMF and World Bank reforms. London: Zed Books, 1997.

COLE, M. Cultural psychology. Harvard: Bellknap Press, 1996.

DE VYLDER. Development strategies, macro-economic policies and the rights of the child. Stockholm, 1996. [Discussion paper for Radda Barnen.]

EU. Quality targets in services for young children. Brussels: European Commission Network on Childcare. European Commission, DGV, 1998. 
EVANS, J. L.; MYERS, R.G.; ILFELD, E. M. Early childhood counts. a programming guide on early childhood care for development. Washington: World Bank. WBI Learning Resources Series, 2000.

GEORGE, S.; SABELLI, F. Faith and credit. the World Bank's secular empire. London: Penguin, 1994.

HANCOCK, G. Lords of poverty. London: Mandarin, 1989.

IDS. Development Research Insights. n. 34. Sep. 2000.

JUBILEE 2000 COALITION. Who will repay the $\$ 450$ billion lent to dictators? Disponível em: www.jubilee2000uk.org/news/dictators

KAGAN, J. Three seductive ideas. Cambridge: Harvard University Press, 1998.

KATZ, L. Presentation at the International Seminar of the annual NAEYCE conference. Toronto, 1998.

MUSTARD, F.; McCAIN, M. Early childhood care and education is good public policy. Ontário: Children's Secretariat, 1999.

MYERS, R. Summary and update: the EFA global thematic review of early childhood care and development, 1999. Disponível em: World Education Forum website.

MYERS, R. Thoughts in the role of the "private sector" in early childhood development. Washington, 2000. [Paper given at World Bank Conference "Investing in our children's future from science to public policy". April 2000.]

OECD. OECD country note: early childhood education and care policy in the United States of America, 2000. Disponível em: <mww.oecd.org>

PENN, H. Early childhood services. theory, policy and practice. Bucks: Open University Press, 2000.

PENN, H. How should we care for babies and toddlers. Toronto: CRRU, Centre for Urban and Community Studies, University of Toronto, 1999.

RAFFER, K. What's good for the United States must be good for the world. Vienna: Kreisky Forum Symposium, 1992. [reprinted by Jubilee 2000]

RAHNEMA, M.; BAWTREE, V. (ed.). The Post development reader. London: Zed Books, 1997.

RAMPAL, S. Debt has a child's face. Disponível em: < unicef.org/pon99/debtcom>

$\mathrm{RICH}$ HARRIS, J. Where is the children's environment? A group socialization theory of development. Psychological Review, v. 102, n.3, p. 458-489, 1995. 
RIST, G. The History of development. from western origins to global faith. London: Zed Books, 1997.

ROSEMBERG, F. The World Bank and ECCE policies for the third world. London, 2000. [Paper given at the EECERA conference August 2000, Institute of Education.]

ROSSETTI-FERREIRA, M. C. Improving early child care and education in developing countries. Stockholm, Sweden, 2000. [Lecture given at the International Congress of Psychology.]

SACHS, W. Planet dialectics. London: Zed Books, 1999.

SCHEPER-HUGHES, N. Death without weeping. Los Angeles: University of California Press, 1993.

SHIVA, V. Respect for the earth. London: BBC, 2000.

SKLAIR, L. (ed.). Capitalism and development. London: Routledge, 1994.

STEPHENS, S. Children and environment: local worlds and global connections. Childhood, v.2, n. 2, p. I-21, 1994.

. Children and nationalism. Childhood, v. 4, n. I, p. 5-17, 1997.

. Children and the politics of culture. New Jersey: Princeton University Press, 1995.

. Children in cold war America. Childhood, v. 4, n. I, p. 103-123, 1997.

STIRRAT, R. Economics and culture: towards and anthropology of economics. In: LEACH, F. E.; LITTLE, A. Education, cultures and economics. London: Falmer, 1999. p. 33-47.

UNDP. Human development report. Oxford: OUR. Human Development Report, 1999.

UNESCO. Promesa: an integrated community-based early childhood education programme carried out by CINDE. In: UNESCO. Early childhood development. laying the foundations of learning. Paris, 1998. p. 66-7I.

. World education forum 2000. Paris: EFA, 2000 (Bulletin. n. 39.)

UNICEF. Child poverty in rich countries. 2000.

. Education for all? Florence: Innocenti Centre, 1998.

WACHS, T.; McCABE, G. The Role of the environment in human nutritional research and intervention in nutrition, health and child development. Washington. Pan American Health Organization; World Bank, 1998. p. 14-29.

WEIKART, D. Presentation at the International Seminar of the annual NAEYC conference. Toronto, 1998. 
WEISBROT, M. et. al. Growth may be good for the poor - but are the IMF and World Bank policies good for growth? A closer look at the World Bank's most recent defense of its policies. Washington: Centre for Economic and Policy Research, 2000.

WOODWARD, D. Debt, adjustment and poverty in developing countries: the impact of debt and adjustment at the household level in developing countries. London: Pinter Publications, SCF, 1992.

WORLD BANK. Annual Report. Washington: World Bank, 1999.

. Early Childhood Development. 2000. Disponível em: < mww.worldbank.org/children> . Early childhood development in Sub-Saharan Africa: issues and strategies. Washington: Findings. 1997. [Africa Region. n, 96] .Introduction 2000. Disponível em <www.ecd.org >

. What is the World Bank's mission. 2000. Disponivel em: <wuw.worldbank.org> . The World Bank and children. Washington: World Bank Social Protection Human Development Network, 2000.

YOUNG, M. E. Policy implications of early childhood development programmes in nutrition, health and child development. Washington: Pan American Health Organization; World Bank, 1998. p. 209-224. 